\title{
Neural Mechanisms of Pain: an Overview
}

\author{
Kenneth L. Casey \\ University of Michigan Medical Center and Veterans Administration Medical Center, Ann Arbor, Michigan, U.S.A.
}

There are two essential components of pain: discriminative and affective. The discriminative component includes the ability to identify the stimulus as originating from somatic or visceral tissue, determine some of the physical properties of the stimulus, and localize it in space, time, and along a continuum of intensities. The affective component is the experience of aversiveness which motivates escape, avoidance, and protective behavior. Both of these components of pain were acknowledged by Sir CHARLes SherRington (1947) and must be considered in any discussion of the neurophysiological basis of pain. The neural mechanisms subserving discrimination and affect are different and may be differentially affected by drugs or surgical procedures.

A consideration of pain mechanisms must also include the neural systems modulating pain, for it is well known that pain can be profoundly influenced by other somatic stimuli and by attentional, emotional, and cognitive factors. A thorough and detailed discussion of pain mechanisms is beyond the scope of this brief overview, but I will cover major features of the neural mechanisms currently thought to underlie the discriminative and affective dimensions of pain and the mechanisms by which pain may be modulated.

\section{PERIPHERAL MECHANISMS}

Receptors uniquely responsive to painful stimuli are found in skin, muscle and deeper tissues. These nociceptors excite afferent discharges in finely myelinated (Aס) or unmyelinated (C) sensory fibers (BURGess \& PERL 1973). Nociceptors appear to be among the group of undifferentiated terminals lacking a specialized transducing apparatus. A structural feature distinguishing nociceptors from all other types of somatic or visceral endings has not been identified. The mechanism by which noxious stimuli activate nociceptors is not known, but chemical events are probably important links between the stimulated tissue and the receptor (KEELE 1970, Burgess \& Perl 1973). Stimuli which are potentially or actually damaging to tissue may release ions or organic substances, such as histamine or specific peptides, which bind specifically to receptors on the terminal membrane, triggering the depolarization which leads to the generation of action potentials in the afferent fiber. This chemoreceptor hypothesis (LIM 1970) would explain why some nociceptors are "polymodal" and respond to any stimulus which threatens tissue integrity. Other nociceptors, however, respond only to intense mechanical or thermal stimuli, a selectivity not easily explained by chemoreceptor mechanisms.

Nociceptors have been studied by recording from the $A \delta$ and $\mathrm{C}$ fiber afferents of experimental animals and humans. Most $\mathrm{A} \delta$ afferents respond to innocuous mechanical or thermal stimuli, but approximately $25 \%$ respond only to strong mechanical (Burgess \& PerL. 1968, PeRL 1968) or thermal (IGGO 1974, Dubner et al. 1974) stimuli. IGGO (1974) has estimated that, in the cat, approximately $20 \%$ of dorsal root fibers are mechanical nociceptors and $30 \%$ are thermal nociceptors. GEORGOPOULOS (1976), however, found that nearly all C fibers innervating the glabrous skin of the monkey were highthreshold mechanoreceptors and/or thermoreceptors. In addition, Besson \& PerL (1969) have identified a significant population of $\mathrm{C}$ polymodal nociceptors which respond to either thermal, mechanical or chemical noxious stimuli.

Some commonly experienced features of pain are at least partially explained by the physiological properties of nociceptive afferents. Noxious thermal stimuli, for example, may induce a prolonged increase in the sensitivity of polymodal nociceptors to mechanical stimuli (PERL 1976) and direct recordings from single nociceptive afferents in the human have indicated that sharp, pricking pain is associated with the activation of A $\delta$ afferents whereas $\mathrm{C}$ fiber discharges are accompanied by more prolonged burning sensations (TOREBJÖRK \& HALLIN 1973, 1974).

Nearly all sensory input from the body or viscera enters the spinal cord via fibers in the dorsal spinal roots. There is now evidence, however, that $20 \%-30 \%$ of the ventral root fibers in cat and man are unmyelinated (Coggeshall et al. 1975) and that, in cat, approximately one-half of these $\mathrm{C}$ fibers are sensory afferents which respond to noxious cutaneous or deep stimuli similar to those which activate $C$ polymodal nociceptors (GuIfTON et al. 1976). The cell bodies of these ventral root nociceptive afferents are in the dorsal root ganglion, 
and their axons terminate in the superficial layers of the dorsal horn (LiGHT \& METZ 1979). It is quite possible that the presence of ventral root nociceptive afferents offers a partial explanation for the frequent failure of dorsal rhizotomy to relieve pain in man. HosobucH (1980), in fact, has recently reported that dorsal ganglionectomy has relieved pain and dysesthesia which had persisted following dorsal rhizotomy.

\section{SPINAL MECHANISMS}

\section{Organization of the spinal cord dorsal horn}

As described by REXED (1952), the spinal gray matter is divided into several cytoarchitecturally distinct regions, or laminae. Lamina I neurons are spindle-shaped cells situated along the outer rim of the dorsal horn where they receive direct input from dorsal root afferents and from neurons of the substantia gelatinosa in laminae II and III. The axons of many of these lamina I neurons cross the midline to ascend in the lateral funiculus to the contralateral posterolateral thalamus. Some of these cells also project to the brainstem reticular formation. Lamina I neurons receive excitatory input from finely myelinated $\mathrm{A} \delta$ or unmyelinated $\mathrm{C}$ peripheral nerve fibers and typically respond differentially or exclusively to noxious stimuli delivered within a cutaneous receptive field covering a small fraction of the surface of a limb (Christensen \& Perl 1970).

Laminae II and III comprise the substantia gelatinosa of the dorsal horn (GoBel 1978). The major cell of lamina II, the stalked cell, has short, stalk-like dendrites which extend medially and ventrally into lamina III. Stalk cell axons penetrate into lamina I, making multiple synaptic contacts with the projection neurons there. Relatively few neurons of laminae II and III send direct projections to the thalamus. Recent physiological studies (CERVERo et al. 1979) have shown that the majority of substantia gelatinosa neurons have a nearly continuous resting discharge rate of $5-10 \mathrm{~Hz}$ in the absence of stimulation applied to the receptive field. In the anesthetized cats studied by Cervero et al. (1979), most substantia gelatinosa cells were inhibited both by noxious and innocuous stimuli; others were selectively inhibited by either noxious or innocuous inputs. CERVERO \& IGGO (1978) have suggested that these interneurons control the responses of dorsal horn projection neurons by releasing them from tonic inhibition when the appropriate stimulus is applied.

Lamina IV contains large neurons with dendrites extending into the substantia gelatinosa to receive input from substantia gelatinosa interneurons and from dorsal root afferents. Lamina IV neurons project to deeper laminae of the spinal gray and also contribute ascending axons to the dorsolateral funiculus primarily of the ipsilateral side. Very few of these cells project directly to the thalamus as determined by the analysis of the retrograde transport of horseradish peroxidase injected into the lateral or medial thalamus (WIL.LIS et al. 1979). A substantial proportion of these neurons, however, project axons to the ipsilateral lateral cervical nucleus via the spinocervical tract of the dorsolateral fasciculus. Physiological studies have shown that most of these cells respond to both innocuous and noxious cutaneous stimuli, including noxious heat (BROWN \& FrANZ 1969).

In the primate, neurons of lamina $\mathrm{V}$, especially those situated laterally, send axons to the contralateral ventral posterolateral thalamus. Lamina $\mathrm{V}$ neurons receive somatic input from both large myelinated and small myelinated and unmyelinated fibers. They characteristically have a wide dynamic range of response to somatic stimuli, showing a relatively brief, low-intensity response to light tactile or other innocuous stimuli but emitting a more rapid and prolonged discharge as stimulus intensity is increased into the noxious range (PRICE \& BROWE 1975). Repetitive electrical stimulation of unmyelinated $\mathrm{C}$ fibers has been shown to result in a progressively enhanced and prolonged response to successive stimuli, referred to as the "windup" phenomenon (Mendell \& Wal. 1964). Lamina V neurons also respond to noxious thermal and chemical stimuli such as peripherally applied bradykinin. Visceral inputs have been shown to activate lamina $V$ cells, but it is not known if the activation of these afferents is noxious. The convergence of visceral and somatic input onto spinothalamic neurons suggests a neurophysiologic basis for the phenomenon of referred pain in which deep or visceral pain is perceived as having a somatic or superficial source (SElzer \& Spencer 1969).

Neurons in deeper laminae, especially VI through VIII, also contribute axons to the spinothalamic system and to ascending systems terminating in the brainstem reticular formation. The neurophysiology of lamina VI-VIII neurons is not known as well as that of cells in the dorsal spinal gray, but some of these deeper cells are known to respond primarily to activation of muscle, joint, and visceral afferents; convergence of deep and cutaneous input has also been demonstrated (FIEI.DS et al. 1977). The receptive fields of these deeper neurons is considerably more extensive than that of lamina I-V cells and often includes more than one limb as well as ipsilateral and contralateral inputs.

In summary, anatomically and physiologically distinct groups of spinal cord neurons are capable of transmitting nociceptive information directly to the thalamus and/or brainstem. Nociceptive specific neurons are found in lamina $I$ and neurons with a wide 
dynamic range, responding differentially to noxious stimuli, are located in lamina V. Neurons in the more ventral laminae VI-VIII respond to stimulation of cutaneous and non-cutaneous afferents; the effective stimuli are clearly noxious in many instances, but this is less certain in the case of non-cutaneous afferent input. Many other neurons without direct supraspinal projections may also be important for pain perception either by their action on spinothalamic neurons or possibly by activation of multisynaptic ascending pathways; the relevant anatomy and physiology of such cells, however, is not known.

\section{Ascending spinal pathways}

This subject has recently been thoroughly reviewed by DENNIS \& MEI.ZACK (1977). They point out that no less than six spinal afferent systems have been identified as capable of transmitting nociceptive information to the brain. The evidence implicating each of these ascending pathways in the mediation of pain sensation, however, varies considerably.

In the cat, nociceptive-specific, postsynaptic fibers have been identified in the dorsal columns (ANGAUTPetiT 1975). A comparable study has not been reported in the primate, but there is behavioral evidence that lesions restricted to the primate dorsal columns reduce reactivity to electric shock without, however, altering the threshold for responding (VIERCK et al. 1971). Cats with spinal lesions sparing only the dorsal columns, however, show no evidence of feeling pain (FrOMMER et al. 1977). The evidence thus far, then, suggests that some dorsal column fibers may be necessary for normal pain reactions but are not alone sufficient for pain sensation.

The spinocervical tract, which ascends in the dorsolateral spinal cord to synapse in the lateral cervical nucleus of carnivores and primates, has been found to contain fibers which are differentially or exclusively responsive to noxious stimuli. There is evidence that this pathway also exists in man although it is less well developed compared with its prominence in other species. Lesions of the spinocervical tract have been shown not to attenuate pain responses in animals, but extensive spinal lesions which spare the dorsolateral cord also preserve pain responses at an elevated threshold (VIERCK et al. 1971). The role of the spinocervical tract in man is completely unknown; in carnivores and subhuman primates, this pathway may contribute to pain but it does not appear to be essential.

Fibers contributing to the spinothalamic tract are found in the lateral and ventral portions of the spinal cord in both carnivore and primate. The cell bodies of spinothalamic neurons are found principally in laminae I, V, and VII-VIII. As indicated earlier in this review, neurophysiological studies have shown that each of these neural populations contains different proportions of neurons responding exclusively or differentially to noxious or innocuous cutaneous stimuli and, in some instances, to activation of deeper receptors in muscles, subcutaneous tissue, or viscera. Whether spinothalamic axons with distinct physiological characteristics are clustered within certain sectors of the spinal cord is not known. The anatomical and physiological evidence indicates, however, that several modalities other than pain are represented within the spinothalamic system. This has been most convincingly revealed in man by the demonstration of the capacity to localize light touch, feel temperature changes, and detect joint movement in a patient with a traumatic thoracic cord lesion sparing only one ventrolateral quadrant (NOORDENBOS \& W WL. 1976). Clinical and animal behavioral studies have also shown that pain can be mediated by fibers ascending throughout much of the ventral cord, not simply the ventrolateral sector. The patient referred to above, for example, could feel deep pain bilaterally; and behavioral studies in monkeys and cats have shown that total bilateral ventral cord lesions are necessary to produce a lasting and significant loss of pain sensitivity (VIERCK \& Luck 1979).

Finally, there is behavioral evidence that, in cat and rat, aversive reactions to noxious somatic stimuli can still be elicited following bilateral spaced hemisections of the spinal cord (BASBAum 1973). These observations indicate that multisynaptic, short-fiber systems within the spinal cord of these species are capable of transmitting nociceptive information to higher centers which mediate pain behavior. There is no clear evidence on this point, however, in man or subhuman primates. HiтcHCOCK (1970) and SchVARCz (1974) have reported that midline upper cervical stereotaxically placed lesions markedly reduce pain sensation over extensive bilateral portions of the entire body below the lesion, but whether this remarkable effect is due to the interruption of a medial, multisynaptic, short-fiber intraspinal system is not known.

\section{SUPRASPINAL MECHANISMS}

Figure 1 diagrammatically summarizes the ascending spinal and supraspinal pathways.

In accord with the division of pain into two essential components, supraspinal structures may be viewed as mediating the discriminative aspects of pain or as subserving nondiscriminative functions such as the initiation of autonomic or complex motor responses and the aversive motivational and affective dimensions of the pain experience. The anatomy and physiology of the 


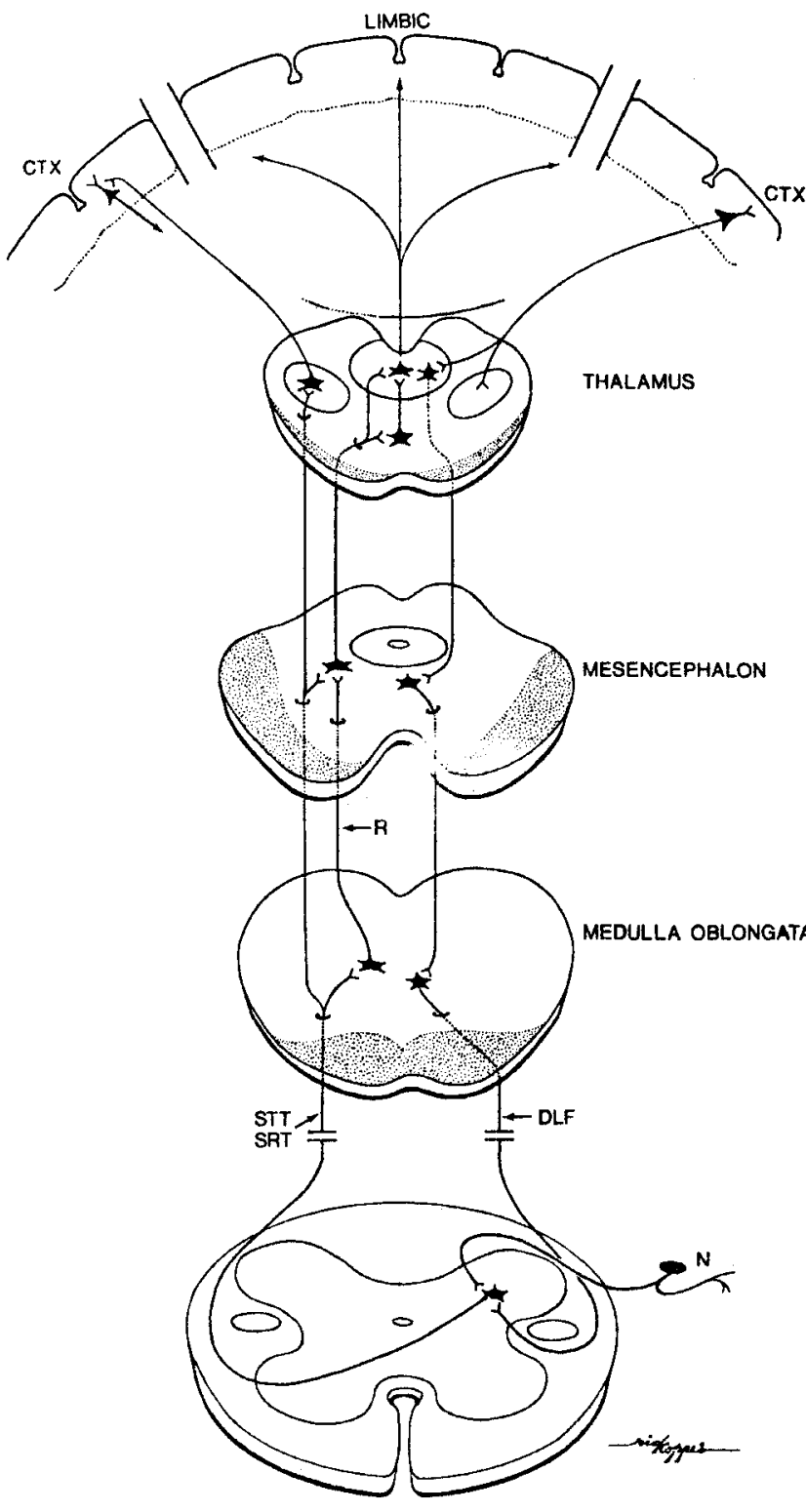

Fig. 1. Central pathways mediating pain (ascending systems on the left of the diagram) and suppression of pain (descending pathway on the right). Nociceptive afferent neurons ( $N$ ) excite dorsal horn cells with axons ascending in the spinothalamic (STT) and spinoreticular (SRT) tract. STT neurons project directly to the posterolateral thalamus where they contact thalamocortical neurons with axons passing to sensory cortex (CTX). SRT neurons project to medullary (MED) and mesencephalic (MES) reticular formation neurons which form a reticulo-thalamic pathway $(R)$ to the posterior medial thalamus (THAL) and hypothalamus. These medial diencephalic neurons have diffuse cortical connections and project to limbic system structures of the forebrain.

Descending pain suppression pathways (shown on right) may include cortical neurons projecting to the posterior lateral and medial (periventricular) thalamic cells. Midline raphe neurons in the mesencephalon and medulla form part of a system descending in the dorsolateral spinal fasciculus (DLF) to suppress nociceptive activation of dorsal horn neurons. discriminative functions are better known than those of the nondiscriminative systems.

\section{Discriminative systems}

The ventrobasal (VB) complex of the dorsal thalamus $(n$. ventralis posterolateralis and medialis) receives input from the contralateral dorsal column nuclei, the trigeminal sensory nucleus, and the spinothalamic tract. In man, lesions within the ventrobasal thalamus produce profound deficits in somesthetic discriminative capacity, but typically fail to achieve lasting analgesia or relief from clinical pain (WhITE \& SwEET 1969). Electrical stimulation within VB of man elicits localized paresthesias which are not described as painful (TALAIRACH et al. 1949), although HALLIDAY \& LOGUE (1972) have elicited reports of localized pain during stimulation within regions caudoventral to this complex. Such stimuli may, however, excite spinothalamic projections to other parts of the brain. Although the great majority of VB neurons respond exclusively to innocuous stimulation within small somatic receptive fields, there is evidence that a small population of VB neurons are excited primarily or exclusively by noxious stimuli (for review, see KERR \& Casey 1978). Kenshalo et al. (1980) have recently reported that an extensive search within VB of the anesthetized monkey revealed a few neurons responsive primarily to noxious heat; some of these cells were found to project to the somatosensory cortex. Perhaps the activation of a rather small population of $\mathrm{VB}$ nociceptive neurons provides sufficient information to identify and localize noxious somatic and visceral stimuli.

The primary somatosensory cortex receiving input from VB thalamic neurons is likewise organized to process discrete temporal and somatotopic information. Neurosurgical experience with localized lesions and electrical stimulation has, as in the VB thalamus, provided little evidence that this cortical area is essential for pain (White \& SweET 1969). Perhaps the most convincing reports supporting the view that a specialized region of the human cerebral cortex is essential for normal pain perception are those presented by MAR- $_{A}$ SHALL (1951). This physician observed that some soldiers who received bullet wounds which apparently grazed the convexity of parietal cortex had marked focal deficits of pain and other somatic senses for years after the injury. There was no histological analysis of the lesions, but surgical and radiographic records clearly indicated that a very restricted portion of the cortex was damaged. Surgical attempts to relieve pain by focal extirpation of sensory cortex, however, have proved so disappointing that the procedure is almost never used. Moreover, the experience of most neurologic physicians is that pronounced somesthetic discriminative deficits 
may follow damage to somatosensory cortex with no alteration of pain sensitivity. Similarly, it has not been possible to demonstrate consistently lasting and specific pain deficits in animals following cortical lesions. Nonetheless, the reports of MARSHALL (1951) and the reports of occasional high threshold neurons recorded from the posterior portion of the secondary somatosensory cortex (Garreras \& Andersson 1963, Whitsel et al. 1969) suggest that some localized cortical regions are important for the normal discrimination and identification of noxious stimuli.

\section{Nondiscriminative systems}

The reticular formation of the medulla and midbrain receives substantial input from fibers ascending in the ventral spinal funiculi (MeHLER et al. 1960). Numerous investigators have found reticular formation neurons, especially in the nucleus gigantocellularis (nGC) (CASEY 1969), which are differentially responsive to noxious somatic stimuli and to visceral input such as high intensity stimulation of the splanchnic nerve (KERR \& CASEY 1978). Speculation about the functional significance of these neurons is complicated by the fact that many nGC cells respond to nonsomatic as well as somatic stimuli and are known to have both ascending projections to the thalamus and descending projections to the spinal cord. Reticulospinal neurons may modulate sensory and motor functions related to pain and pain responses. It is highly unlikely that the reticulothalamic component of the nGC projection subserves any spatial, temporal, or modality-specific discriminative function because the reticular neurons respond to somatic stimuli delivered throughout much of the body, may respond to non-somatic stimuli, and project to the posterior hypothalamus and the medial and intralaminar thalamic nuclei which do not subserve somesthetic discriminative functions. There is evidence, nonetheless, that nGC activity is an important determinant of pain behavior since, in the awake cat, the driven activity of such neurons has been correlated with escape from somatic stimuli, localized electrical stimulation with nGC elicits escape and related pain behaviors, and nGC lesions significantly attenuate pain behavior without affecting motor responses (CASEY 197la, 1971b, 1971c, 1980). Although all these effects could be spinally mediated, it is likely that the reticulodiencephalic projections, especially those to the hypothalamus, are necessary for the autonomic and motivational-affective components of pain. The same comments apply to the midbrain reticular formation, for neurons there also project to the medial thalamus and hypothalamus, lack the physiological properties expected of somesthetic discriminative neurons, and have been shown, by stimula- tion and lesion studies, to mediate pain-related behavioral responses (OLDS \& OLDS 1963). In addition, certain neurons in the medial mesencephalic reticular substance may activate descending sensory controls to modulate pain, as discussed elsewhere in this review.

Thalamic neurons differentially responsive to noxious stimuli have been recorded from the posterior nucleus (PO) and from nuclei of the medial and intralaminar thalamus in cat and monkey (Poggio \& Mountcastle 1960, Casey 1966, Dong et al. 1979). The receptive fields of these cells, and of those responding to innocuous stimuli, are large and often bilateral, suggesting that these thalamic nuclei play little or no role in discriminative processes. Lesions involving the PO and intralaminar region, however, have been reported to relieve intractable pain in man (HASSLER 1960, MARK et al. 1963, SANO 1967) and markedly attenuate pain responses in cats (MrTChell \& KAEI.BER 1966). In the patients, there is no apparent loss of discriminative capacity, so the effect has been attributed to a loss of the affective component of pain. The observations of KEENE (1973) support this speculation. He found that the discharge of neurons recorded from the rat intralaminar thalamus was decreased for several seconds by brief electrical stimulation of "reward" sites in the medial forebrain bundle, but showed prolonged increases following similar stimulation at behaviorally aversive sites in the midbrain reticular formation. Nonetheless, it would not be appropriate to designate medial or intralaminar thalamic neurons as exclusively concerned with some aspect of pain because many of these neurons receive input from other sensory modalities and from motor systems such as the striatum and cerebellum. Perhaps neurons in this part of the diencephalon also mediate specific motor response patterns associated with highly arousing stimuli.

The effect of small lesions within the cingulum bundle or in posteromedial frontal white matter provides additional evidence that a critical, nondiscriminative component of pain is mediated by structures outside established somatovisceral pathways. Cingulumotomy or frontal leukotomy have been shown to provide very effective relief from intractable pain in man (KERR \& Casey 1978, White \& Sweet 1969, Foltz \& White 1962). According to Sweet (KerR \& Casey 1978), postoperative changes in affect, emotional spontaneity, and other aspects of personality can be avoided by the proper stereotaxic placement of small lesions. The patient's discriminative capacity is preserved, but the affective tone associated with chronic pain is markedly diminished or absent. Since both these procedures interrupt connections within the limbic lobe of the forebrain, the results emphasize the critical role of the limbic system in 
the mediation of the affective-motivational component of pain.

\section{THE MODULATION OF PAIN}

Figure 1 diagrammatically summarizes the descending pathways currently thought to modulate pain.

\section{Afferent mechanisms}

Complex interneuronal interactions within the spinal cord dorsal horn on trigeminal sensory nucleus provide the basis for the modulation of pain by afferent fibers. In the gate control hypothesis advanced by MELzACK \& WAI.I. (1965), neurophysiological evidence (MENDELL \& WAL.L. 1964) was cited to support the idea that activity in unmyelinated $\mathrm{C}$ fibers enhanced, and large myelinated A fibers reduced, synaptic transmission from somatic sensory afferents. Subsequent experiments (JANIG \& Zimmerman 1971, WhiteHorN \& BuRgess 1973) have shown that both $\mathrm{A}$ and $\mathrm{C}$ fibers can attenuate the excitatory effects of afferent volleys. In any case, there is general agreement that the excitability of dorsal horn or trigeminal nucleus neurons projecting to the brain is not simply determined by the intensity of nociceptive afferent discharge, but is strongly influenced by ongoing activity in other sensory afferents serving the same or adjacent spinal segments. These afferents excite dorsal horn neurons, such as those within the substantia gelatinosa (CERvero et al. 1979), which can act presynaptically or post-synaptically to attenuate, or possibly enhance, the discharge of other spinal sensory cells projecting to the brain or brain stem. The most common, and perhaps the most convincing, evidence that stimulation of cutaneous afferents can strongly influence ongoing cutaneous sensation is that scratching relieves itching. Sometimes, pain may also be partly relieved by activating cutaneous afferents by natural or electrical stimulation.

\section{Central mechanisms}

It has been shown in animals that electrical stimulation within certain parts of the CNS can produce an analgesia which typically outlasts the duration of stimulation. Stimulation-produced analgesia (SPA) has been most consistently demonstrated by stimulation within the midline raphe nuclei of the brain stem, a group of serotonin-containing neurons extending from the mesencephalon through the medulla (LiEBESKIND 1976). The axons of medullary raphe cells descend in the dorsolateral fasciculus (DLF) to terminate in the dorsal horn where they markedly attenuate the response of spinothalamic and other dorsal horn cells to noxious stimuli. Surgical section of the DLF eliminates this suppressive effect and prevents the analgesic effect induced by stimulating the medullary raphe (BASBAUM et al. 1976). Some experiments have suggested that the cerebral cortex may also participate in this system.

The mechanisms underlying SPA appear to be closely related to the analgesia produced by morphine in experimental animals. Raphe system lesions, DLF lesions and blockage of the synthesis of serotonin within raphe neurons all reduce the analgesic effect of morphine and SPA. Furthermore, naloxone reverses the analgesia of both morphine and SPA, and repeated exposure to SPA or morphine results in the development of tolerance to either agent (MAYER \& Price 1976). The possible activation of an active and specific painsuppression mechanism by morphine suggested that there may be endogenous opiate-like substances in the brain which are important for the normal, physiological operation of this system. Recent work has, in fact, supported this hypothesis. Radioactive labeling of opiate agonists reveals the presence of opiate receptors in the brain (PERT \& SNYDER 1973). The opiate receptors are found at several CNS sites, but the binding with opiate agonists is most dense in portions of the limbic system, medial thalamus and the periaqueductal gray of the midbrain (KuHAR et al. 1973). In the spinal cord, opiate receptors occur in the substantia gelatinosa of the dorsal horn where a significant proportion seem to be located on the membranes of primary afferent terminals (LAMotTE et al. 1976).

The discovery of opiate receptors in the CNS was followed by the finding that the mammalian brain synthesizes small peptides with opiate-like pharmacologic properties (Hughes et al. 1975). There are two pentapeptides (composed of five amino acids), called enkephalins, which have a CNS distribution similar to that of the opiate receptors. The amino acid sequence of each peptide is identical, except that metenkephalin has methionine in the terminal position where leu-enkephalin has leucine. Both met- and leu-enkephalin are derived from the intraneuronal ribosomal synthesis of a precursor protein which is then subjected to proteolytic cleavage by specific enzymes to form the smaller pentapeptides. The type of opioid peptide contained in a neuron appears to depend on the type of cleavage enzyme available. In the brain, there are met-enkephalin- and leu-enkephalin-containing neurons; in the hypothalamopituitary system, it seems that the same (or very similar) precursor protein is cleaved into corticotropin, or $\beta$-lipotropin, or a larger opioid peptide, $\beta$ endorphin, in different neurons (GOLDSTEIN 1976).

The enkephalins are released from the terminals of short-axon interneurons to act as neuromodulators or perhaps as neurotransmitters to modulate synaptic 
transmission between neurons mediating pain (KOSTERI.ITZ \& Hughes 1975). Both met-enkephalin and leuenkephalin are released from brain slices and from isolated synaptic endings (synaptosomes) by potassium ions, veratridine and electrical stimulation; this release is enhanced by calcium and is blocked by lack of calcium and by tetrodotoxin, consistent with the expected effects on normal synaptic release mechanisms. In the brain, enkephalin-containing nerve processes and endings have been identified by immunohistochemical methods. The release of enkephalin from these endings is likely to have powerful effects on synaptic transmission since, like morphine, met-enkephalin has been shown to inhibit cholinergic, adrenergic and dopaminergic transmission. The enkephalins also may inhibit the release of another peptide, substance $P$, which is found in the terminals of sensory afferents in the dorsal horn of the spinal cord and in the trigeminal nucleus (HökfELT et al. 1975).

A major problem is to demonstrate both the normal physiological mechanisms of activation of the proposed pain-suppression system and the behavioral states in which such activation occurs. There is little evidence, for example, that the administration of the opiate antagonist naloxone has any effect on the pain threshold of normal humans or experimental animals. This may indicate that the enkephalinergic pain attenuation mechanisms are not tonically active, but are brought into play only under special circumstances. If future research reveals more about the normal activation of enkephalin-mediated pain suppression, perhaps we will be able to develop more effective means of controlling pain where current methods are unsatisfactory.

\section{REFERENCES}

Angaut-Petit, D. (1975) The dorsal column system: II Functional properies and bulbar relay of the postsynaptic fibres of the cat's fasciculus gracilis. Exp. Brain Res. 22, 471.

Basbaum, A. I. (1973) Conduction of the effects of noxious stimulation by short-fiber multisynaptic systems of the spinal cord in the rat. Exp. Neurol. 40, 699.

Basbaum, A. I. et al. (1976) Spinal cord pathways involved in the production of analgesia by brain stimulation. Advances in Pain Research and Therapy, Vol. $l$, ed. J. J. BOnICA \& D. G. Al.BE-FesSARD, Raven Press, New York, p. 511.

Besson, P. \& PeRl, E. R. (I969) Response of cutaneous sensory units with unmyelinated fibers to noxious stimuli. 7 . Neurophysiol. 32, 1025.

Brown, A. G. \& FrANz, D. N. (1969) Responses of spinocervical tract neurons to natural stimulation of identified cutaneous receptors. Exp. Brain Res. 7, 231.

Burgess, P. R. \& PerL, E. R. (1968) Myelinated afferent fibers responding specifically to noxious stimulation of the skin. $\mathcal{J}$. Physiol. 190, 541.
Burgess, P. R. \& Perl, E. R. (1973) Cutaneous mechanoreceptors and nociceptors. Handbook of Sensory Physiology, Vol. II, ed. A. IG;o. Springer-Verlag, New York, p. 29.

Garreras, M. \& Andersson, S. A. (1963) Functional properties of neurons of the anterior ectosylvian gyrus of the cat. $\mathcal{J}$. Neurophysiol. 26, 100.

CASEY, K. L. (1966) Unit analysis of nociceptive mechanisms in the thalamus of the awake squirrel monkey. 7. Neurophysiol. 29, 727.

CASEY, K. L. (1969) Somatic stimuli, spinal pathways, and size of cutaneous fibers influencing unit activity in the medial medullary reticular formation. Exp. Neurol. 25, 35.

CASEY, K. L. (1971a) Escape elicited by bulboreticular stimulation in the cat. Int. 7. Neurosci. 2, 29.

CASEY, K. L. (1971 b) Responses of bulboreticular units to somatic stimuli eliciting escape behavior in the cat. Int. J. Neurosci. 2, 15.

CASEY, K. L. (1971c) Somatosensory responses of bulboreticular units in awake cat: relation to escape-producing stimuli. Science 173, 77.

CASEY, K. L. (1980) Reticular formation and pain: Toward a unifying concept. Pain, ed. J. J. Bonica. Raven Press, New York, p. 93.

Cervero, F. \& IGGO, A. (1978) Reciprocal sensory interaction in the spinal cord. 7. Physiol. 284, 84.

Cervero, F. et al. (1979) An electrophysiological study of neurones in the substantia gelatinosa Rolandi of the cat's spinal cord. Quart. F. exp. Physiol. 64, 297.

Christensen, B. R. \& Perl., E. R. (1970) Spinal neurons specifically excited by noxious or thermal stimuli: Marginal zone of the dorsal horn. 7. Neurophysiol. 33, 293.

Cutfron, G. L. et al. (1976) Receptive fields of unmyelinated ventral root afferent fibres in the cat. 7 . Physiol. 256, 573.

Coggeshall, R. E. et al. (1975) Unmyelinated axons in human ventral roots, a possible explanation for the failure of dorsal rhizotomy to relieve pain. Brain 98, 157.

Dennis, S. G. \& Melzack, R. (1977) Pain-signalling systems in the dorsal and ventral spinal cord. Pain 4, 97.

Dong, W. K. et al. (1979) Nociceptive responses of neurons in medial thalamus and their relationship to spinothalamic pathways. J. Neurophysiol. 41, 1592.

Dunner, R. et al. (1974) The response of trigeminal afferent fibers to noxious thermal stimuli. Advances in Neurology, Vol. 4, ed. J. J. BonICA. Raven Press, New York, p. 61.

Fiel.ds, H. L. et al. (1977) Somatosensory properties of spinoreticular neurons in the cat. Brain Res. 120, 49.

Foltz, E. L. \& White, L. E. (1962) Pain "relief" by frontal cingulumotomy. J. Neurosurg. 19, 89.

Frommer, G. P. et al. (1977) Somatosensory function and cortical unit activity in cats with only dorsal column fibers. Exp. Brain Res. 27, 113.

GEORGOPOULOS, A. P. (1976) Functional properties of primary afferent units probably related to pain mechanisms in primate glabrous skin. 7. Neurophysiol. 39, 71.

Goвel, S. (1978) Golgi studies of the neurons in layer II of the dorsal horn of the medulla (trigeminal nucleus caudalis). J. comp. Neurol. 180, 395.

Goldstein, A. (1976) Opioid peptides (endorphins) in pituitary and brain. Science 193, 1081.

Halliday, A. M. \& Logue, V. (1972) Painful sensations evoked by electrical stimulation in the thalamus. Neurophysiology Studied in Man, ed. G. G. Somjen. Excerpta Medica, Amsterdam, p. 221.

Hassler, R. (1960) Die zentralen Systeme des Schmerzes. Acta neurochinurg. 8, 353.

Hгтснсоск, E. (1970) Stereotactic, cervical myelotomy. J. Neurol. Neurosurg. Psychiat. 33, 224.

Hökfelt, T. et al. (1975) Experimental immunohistoch emical studies 
on the localization and distribution of substance $P$ in cat primary sensory neurons. Brain Res. 100, 235.

HosobuchI, Y. (1980) The majority of unmyelinated afferent axons in human ventral roots probably conduct pain. Pain 8, 167.

Hughes, J. et al. (1975) Identification of two related pentapeptides from the brain with potent opiate agonist activity. Nature 258, 577.

IgGo, A. (1974) Pain receptors. Recent Advances on Pain: Palhophysiology and Clinical Aspects, ed. P. Procacci \& C. A. PaGni. Thomas, Springfield, Illinois, p. 3.

Janic, W. \& Zimmermann, M. (1971) Presynaptic depolarization of myelinated afferent fibers evoked by stimulation of cutaneous C fibers. 7. Physiol. (Lond) 216, 77.

Keele, C. A. (1970) Chemical causes of pain and itch. Ann. Rev. Med. 21, 67.

KEENE, J. J. (1973) Reward-associated inhibition and pain-associated excitation lasting seconds in single intralaminar thalamic units. Brain Res. 64, 211.

Kenshalo, D. R., JR et al. (1980) Responses of neurons in primate ventral posterior lateral nucleus to noxious stimuli. 7. Neurophysiol. 43, 1594.

Kerr, F. W. L. \& Casey, K. L. (1978) Neurosciences Research Program Bulletin. The MIT Press, Cambridge, Massachusetts.

Kosterlitz, H. W. \& Hughes, J. (1975) Some thoughts on the significance of enkephalin, the endogenous ligand. Life Sci. 17, 91.

KUHAR, M. J. et al. (1973) Regional distribution of opiate receptor binding in monkey and human brain. Nature 245, 447.

LAMOTTE, C. et al. (1976) Opiate receptor binding in primate spinal cord: distribution and changes after dorsal root section. Brain Res. 112, 407.

Lieseskind, J. C. (1976) Pain modulation by central nervous system stimulation. Advances in Pain Research and Therapy, Vol. I, ed. J. J. Bonica \& D. G. At.be-Fessard. Raven Press, New York, p. 445.

LiGHT, A. R. \& METz, D. B. (1978) The morphology of the spinal cord efferent and afferent neurons contributing to the ventral roots of the cat. F. comp. Neurol. 179, 501.

Liм, R. K. S. (1970) Pain. Ann. Rev. Physiol. 32, 269.

Mark, V. H. et al. (1963) Stereotactic thalamotomy. Arch. Neurol. (Chic.) 8, 528.

Marshal., J. (1951) Sensory disturbances in cortical wounds with special reference to pain. 7. Neurol. Psychiat. 14, 187.

Mayer, D. J. \& PRice, D. D. (1976) Central nervous system mechanisms of analgesia. Pain 2, 379.

MEHLER, W. H. et al. (1960) Ascending axon degeneration following anterolateral cordotomy. An experimental study in the monkey. Brain 83, 718.

Mel_ACK, R. \& WAlL, P. D. (1965) Pain mechanisms: A new theory. Science 150, 971.

Mendell., L. M. \& Wall, P. D. (1964) Presynaptic hyperpolarization: A role for fine afferent fibres: 7. Physiol. 172, 274.

Mrtchel., C. L. \& KaEL Ber, W. W. (1966) Effect of medial thalamic lesions on responses elicited by tooth pulp stimulation. Amer. $\mathcal{J}$. Physiol. 210, 263.

NoORdenbos, W. \& WaLl, P. D. (1976) Diverse sensory functions with an almost totally divided spinal cord. A case of spinal cord transection with preservation of part of one anterolateral quadrant. Pain 2, 185.

Otns, M. E. \& OıDs, J. (1963) Approach-avoidance analysis of rat diencephalon. 7. comp. Neurol. 120, 259.

PERI, E. R. (1968) Myelinated afferent fibers innervating the primate skin and their response to noxious stimuli. $\mathcal{f}$. Physiol. (Lond.) 197, 593.
PerL, E. R. (1976) Sensitization of nociceptors and its relation to sensation. Advances in Pain Research and Therapy, Vol. I, ed. J. J. Bonica \& D. G. Al.be-Fessard. Raven Press, New York, p. 17.

Pert, C. B. \& Snyder, S. H. (1973) Opiate receptors: demonstration in nervous tissue. Science 179, 1011.

Pogcio, G. F. \& Mountcastle, V. B. (1960) A study of the functional contributions of the lemniscal and spinothalamic systems to somatic sensibility. Bull. Fohns Hopkins Hosp. 108, 266.

Price, D. D. \& Browe, A. C. (1975) Responses of spinal cord neurons to graded noxious and non-noxious stimuli. Exp. Neurol. 48, 201.

REXED, B. (1952) The cytoarchitectonic organization of the spinal cord in the cat. 7. comp Neurol. 96, 415.

SANO, K. (1967) The role of the internal medullary lamina in pain. Anales del XII Congresso Latino Americo de Neurochirurgia, Lima, Peru, p. 937.

Schvarcz, J. R. (1974) Spinal cord stereotactic surgery. Recent Progress in Neurological Surgery, ed. K. SANO, S. IsHn \& D. I.tVAY: American Elsevier Publishing Company, Inc, New York, p. 234. Selzer, M. \& Spencer, W. A. (1969) Convergence of visceral and cutaneous afferent pathways in the lumbar spinal cord. Brain Res. 14, 331 .

Sher Rington, C. (1947) The Integrative Action of the Nerrous System. Yale University Press, New Haven.

TALAirach, J. et al. (1949) Recherches sur la coagulation thérapeutique des structures sous-corticale chez l'homme. Ret. Neturol. $81,4$.

Torebjörx, H. E. \& Hallin, R. G. (1973) Perceptual changes accompanying controlled preferential blocking of $\mathrm{A}$ and $\mathrm{C}$ fibre responses in intact human skin nerves. Exp. Brain Res. 16, 321,

TOREBJÖRK, H. E. \& HaLliN, R. G. (1974) Identification of afferent $\mathrm{C}$ units in intact human skin nerves. Brain Res. 67, 387.

VIERCK, C. J, JR et al. (1971) Pain reactivity of monkeys after lesions to the dorsal and lateral columns of the spinal cord. Exp. Brain Res. 13, 140.

VisRCK, C. J., JR. \& Luck, M. M. (1979) Loss and recovery of reactivity to noxious stimuli in monkeys with primary spinothalamic cordotomies, followed by secondary and tertiary lesions of other cord sectors. Brain 102, 233.

White, J. C. \& SWEet, W. H. (1969) Pain and the Veurosurgeon. A Forty-year Experience. Thomas, Springfield, Illinois.

WhitehorN, D. \& Burgess, P. R. (1973) Changes in polarization of central branches of myelinated mechanoreceptor and nociceptor fibers during noxious and innocuous stimulation of the skin. 7. Neurophysiol. 36, 226.

Whitsel, B. L. et al. (1969) Symmetry and connectivity in the map of the body surface in somatosensory area II of primates. 7. Neurophysiol. 32, I70.

WILl.IS, W. D. et al. (1979) The cells of origin of the primate spinothalamic tract. $\mathcal{f}$. comp. Neurol. 188, 543.

Address:

Kenneth L. Casey, M.D.

Chief, Neurology Service (127)

Veterans Administration Medical Center

2215 Fuller Road

Ann Arbor, MI 48105

U.S.A. 